\title{
Stress and Coping Patterns of University Students
}

\begin{abstract}
Stress is a common experience for university students. Elevated stress with limited healthy coping capabilities may result in students turning to external resources such as substance use (alcohol and drugs) to cope. Undergraduate students $(\mathrm{N}=5,917)$ were surveyed to examine the relationship between perceived stress and engagement in substance use coping. Results indicate that higher stress is associated with students' reports of unhealthy coping. Interestingly, reports of stress and substance use coping were higher in later university years. These findings suggest the need for increased efforts to integrate programming on healthy coping across all years in university.
\end{abstract}

The experience of stress is common among university students. Students' choice of strategies to cope with this stress has important implications for their physical, psychological, behavioral and academic well-being (Brougham, Zail, Mendoza, \& Miller, 2009). Although the classification of specific coping behaviors into different coping styles is an ongoing debate (Brougham et al., 2009; Dyson \& Renk, 2006; Lazarus \& Folkman, 1984; Palmer \& Rodger, 2009), it is generally agreed that reliance on substance use is an indication of a maladaptive coping process. University administrators remain concerned about students' substance use on campus and are continually looking for further explorations into the factors surrounding students' substance use (Adlaf, Demers, \& Gliksman, 2005). Building on past research on stress and substance use (Chen \& Feely, 2015; Digdon \& Landry, 2013; Kuntsche, Knibbe, Gmel, \& Engels, 2005; Rutledge \& Sher, 2001; Tomaka, Morales-Monks, \& Shamaley, 2013; Welle \& Graf, 2011; Woolman, Becker, \& Klanecky, 2015), we investigated the relation between university students' stress and their use of substances as a coping strategy to assess whether the 
association between stress and substance use is different for males versus females or across year of study.

\section{STRESS}

According to Lazarus and Folkman's (1984) cognitive appraisal theory of stress, psychological stress can result when individuals perceive environmental demands to be a threat to their own well-being. The appraisal component refers to the weighing of situational demands against one's personal ability to cope. If environmental demands are perceived to outweigh the resources, the individual experiences stress; therefore, this transactional process significantly influences individuals' perception of psychological stress and the subsequent coping behavior in which they engage.

Psychological stress is not a new problem for university students; however, it has emerged as an issue of increasing concern, particularly within the context of increased efforts to curb student attrition (Childs, Finnie, \& Martinello, 2016). Durand-Bush, McNeill, Harding, and Dobransky (2015) surveyed students at a Canadian university and found that, compared to the findings of earlier studies using the same measure (Cohen, Karmarck, \& Mermelstein, 1983; Palmer \& Rodger, 2009), students reported higher levels of stress. Reports of increased stress are problematic due to the numerous negative outcomes that can follow or co-occur with experiences of high stress. For instance, higher reports of stress have been associated with poorer academic performance (Pluut, Curşeu, \& Ilies, 2015; Stoliker \& Lafreniere, 2015), poor sleep quality and sleep disturbances (Galambos, Vargas Lascano, Howard, \& Maggs, 2013; Lovell, Nash, Sharman, \& Lane, 2015), decreased tendency to engage in healthy eating (El Ansari, Adetunji, \& Oskrochi, 2014), as well as an increased consumption of alcohol, nicotine, and illicit drugs 
(Adlaf et al., 2005). Stress related to academic workload has also been shown to have an indirect, negative affect on academic satisfaction (Pluut et al., 2015).

In addition to these negative outcomes associated with stress, studies have also documented a number of adverse psychological consequences (Durand-Bush et al., 2015; Holinka, 2015; Price, McLeod, Gleich, \& Hand, 2006). Price et al. (2006) hypothesized that the stress students experience in university may result in an amplified prevalence of mental health disorders within the student population, such as major depressive disorder and major anxiety disorder. In line with this prediction, they found that these disorders were more prevalent in the university student sample compared to the general population. This is in agreement with later studies that found associations between stress and other general health outcomes. For instance, students reporting moderate to high levels of stress were found to exhibit lower levels of mental health functioning.

Holinka (2015) found a significant negative correlation between stress and life satisfaction in a university student sample. Although definitive causal conclusions cannot be reached regarding stress levels and these behavioral, psychological, and health consequences for university students, high levels of stress appear to be associated with adverse outcomes.

To gain a more procedural understanding of what stress entails and its eventual consequences, consideration must also be given to the precedents of stress in university. Sources of stress for university students can vary, and gender has been found to have an impact on the experience of stress; for instance, female undergraduate students were found to attribute significantly greater stress to familial relationships, finances, daily hassles, and social relationships compared to males (Brougham et al., 2009). Interestingly, there was no difference between females and males in the levels of stress attributed to academic stressors, so there may 
not be a conclusive pattern for the sources to which university students attribute their stress. When designing stress-management interventions, while it is important to investigate the various stressors that students reveal, the variability in the pattern prevents generalizable conclusions when examining specific stressors. It is equally important to understand the underlying issues that give rise to stress for university students; however, the cognitive appraisal theory of stress states that the transactional process of weighing environmental demands and personal resources are ultimately uniform across individuals; therefore, the unique stressors and coping resources will vary greatly across individuals while the common variable amongst them will be the experience of stress, albeit to differing degrees (Lazarus \& Folkman, 1984). Measuring the stress experience can be valuable in furthering our understanding of the stress profile of university students.

\section{COPING}

Stress is a part of academic life, and students often find themselves in search of strategies to mitigate its effects, that is, coping — defined as "constantly changing cognitive and behavioral efforts to manage specific external and/or internal demands that are appraised as taxing or exceeding the resources of the person" (Lazarus \& Folkman, 1984, p. 141). Several attempts have been made to classify coping styles due to the breadth of this construct. For instance, Lazarus and Folkman (1984) have proposed two coping styles based on empirical evidence: problem-focused coping and emotion-focused coping. The former refers to coping that focuses on addressing the problem that is causing the stress experience, whereas the latter is a coping approach that focuses on regulating the emotions that arise from the experience of stress; however, the authors have acknowledged that this dichotomous model may be limited when categorizing the multitude of coping behaviors in which individuals may choose to engage: 
namely, that there may be certain behaviors that do not neatly fit into the problem-focused or emotion-focused categories of coping.

Coping styles and behaviors have also been described based on their outcomes as either adaptive or maladaptive (Brougham et al., 2009); however, this method of categorization can also be problematic. In their study of stress and coping in university students, Palmer and Rodger (2009) concluded that coping styles considered to be maladaptive may not always lead to negative outcomes, and those considered adaptive may not consistently lead to positive outcomes; therefore, it is important to note that the debate concerning the description of coping styles and their subsequent categorization based on outcome is ongoing (Brougham et al., 2009). For this reason, it may be more theoretically plausible to look at specific behaviors that are reported to serve the purpose of coping when comparing the stress and coping profiles reported across different studies. With this approach, the variance in the model of coping style used in different studies will not distort the validity of comparing study findings.

One such behavior that is widely studied on university campuses is the problematic consumption of alcohol. The availability and accessibility of alcohol for university students varies depending on regional laws; therefore, it is important to note that in Quebec individuals may legally purchase and consume alcohol from the age of 18 years, while the legal age in other Canadian provinces and territories is 19 (e.g., Ontario). The Canadian Campus Survey conducted in 2004 reported on the alcohol consumption patterns of 6,282 university students across Canada (Adlaf et al., 2005). According to this report, 33.3\% of the sample reported heavy drinking patterns (e.g., more than 5 drinks on drinking days), and $16.1 \%$ of these reported engaging in this pattern of consumption on a weekly basis. Similarly, the National College Health Assessment survey conducted by the American college Health Association in the United States, where the 
age of legal alcohol consumption is 21 years, found that $28.3 \%$ of undergraduate students reported engaging in high-risk drinking, defined as more than 5 drinks in one sitting (ACHA, 2018). Correspondingly, the proportion of students who engaged in high-risk drinking was $35 \%$ of the 43,000 that responded to the NCHA survey in Canada (ACHA, 2016). Heavy patterns of drinking were found to be linked to numerous adverse outcomes including accidents, episodes of violence and alcohol poisoning, whereby the possibility of encountering an adverse consequence of drinking was found to increase with the number of drinks consumed (Adlaf et al., 2005). Some of the adverse effects of drinking as reported by students included hangovers, memory loss, regrets, and missing classes as a result of hangovers. In a more recent survey of 760 university students by Collins and colleagues (2014), hangovers and physical effects such as nausea and headaches were also commonly cited as disadvantages to drinking. These researchers also found that the financial cost of drinking was the second most frequently cited disadvantage followed by the interference of alcohol with goals or priorities. Behavioral consequences of intoxication were also mentioned in both studies, including drunk texting, doing stupid things (Collins et al., 2014), unplanned sexual relations, driving after reaching intoxication, engaging in unprotected sex, and driving while drinking (Adlaf et al., 2005). In addition, students also reported harm that could result from other students' drinking, such as interruptions to study or sleep, serious arguments, assaults, and sexual harassment (Adlaf et al., 2005).

Although alcohol consumption among young adults is widely regarded as a social activity and interpersonal factors are thought to play a large role in individuals' decisions to engage in the behavior (see review by Kuntsche et al., 2005), the factors that contribute to drinking motivated as a means of coping among university students warrant further investigation. Research has shown that drinking behavior can be motivated by other factors stemming from 
personal experience, referred to as drinking motives in the literature (Cox \& Klinger, 1988). Cox and Klinger (1988) proposed a motivational model of alcohol use whereby the expected affective outcomes of drinking play a large role in an individual's eventual decision to drink (or not to drink). The authors described the expected outcomes as falling within four broad categories where alcohol consumption is expected to: (a) enhance positive affect, reduce positive affect, (c) reduce negative affect, or (d) intensify negative affect. The drinking motive where individuals wish or expect to reduce negative affect can be referred to as a coping motive for the consumption of alcohol. In this case, individuals may engage in drinking behavior with the expectation that it will reduce negative affect, regardless of whether their consumption of alcohol actually serves this purpose. Coping through drinking has been linked with problematic consumption of alcohol (Kuntsche et al., 2005; Sebena, El Ansari, Stock, Orosova, \& Mikolajczyk, 2012). Goldstein and Flett (2009) reported that alcohol consumption was higher among those who scored high on the coping subscale of the Drinking Motives QuestionnaireRevised (Cooper, 1994) compared to those whose scores corresponded to the category for drinking that is not internally motivated. In addition, Merrill and Read (2010) found that students endorsing alcohol use as a coping mechanism were found to experience difficulties such as poor academic or professional performance, poor self-care, and greater engagement in risk-taking behaviors, regardless of their level of drinking. As such, students reporting coping motivations for alcohol consumption may be at a heightened risk for experiencing harmful consequences.

A related problematic behavior within university student populations is the use of illicit drugs. The legality of substances is generally uniform across Canada in contrast to the United States where the legality of a drug like cannabis varies by state. Although the Canadian government recently passed legislation allowing the recreational use of cannabis, this substance 
remained illegal for recreational use until October 17, 2018. In surveying 9,282 undergraduates in Canadian universities through a national survey, Adlaf et al. (2005) found that $51.4 \%$ of students reported using cannabis in their lifetime, while $32.1 \%$ had used it in the past year and $16.7 \%$ in the past month. Hallucinogens were the second most widely used class of illicit drugs with $16.9 \%$ of students reporting use in their lifetime. Consequences of drug use for university students have also been documented with students reporting moderate to severe physical, psychological, and social consequences (Arria, Caldeira, Bugbee, Vincent, \& O’Grady, 2015; Holloway, Bennett, Parry, \& Gorden, 2014).

Unlike the extensive research documenting the relationship between coping motives and alcohol use, the literature is limited in reporting on the relationship between coping motivation and illicit drug use (McCabe et al., 2005). Using scales to assess frequency of cannabis use and cannabis-related problems in relation to coping motivations, Simons, Gaher, Correia, Hansen, and Christopher (2005) found that coping motives were directly associated with reports of cannabis-related problems. Coping motives were found to be a significant predictor of cannabis use in their sample of 309 university students. Therefore, a similar association exists between coping motives and problematic outcomes for both alcohol use and cannabis use; however, the factors that contribute to engagement in coping through substance use warrant further inquiry.

Research has suggested that stress could be a plausible candidate as the precursor to adopting a coping framework that involves engaging in substance use. Through a large-scale survey of 2,529 university freshmen across 5 European countries, Sebena and colleagues (2012) found that perceived stress was associated with problem drinking behaviors. Given that the association between coping motivation and problem drinking has been documented (Dermody, Cheong, \& Manuck, 2013; Kuntsche et al., 2005), it is plausible to assume that there may also be 
an association between stress and engaging in frequent alcohol consumption specifically as a coping strategy. Stress is also regarded as a general risk factor for substance addiction (Sinha, 2008); however, researchers investigating the link between stress and general substance use in a college student population found it also served as a risk factor for substance use within their sample (Coleman \& Trunzo, 2015). Given these findings, it is apparent that perceived stress, coping motivation, and substance use (alcohol or illicit drugs) are closely linked. This is a relationship that is consistent with the postulations of Lazarus and Folkman's (1984) cognitive appraisal theory of stress: individuals who perceive environmental demands to exceed their personal resources to meet those demands may turn to external resources (i.e., illicit drugs or alcohol) to cope with this perceived stress. Investigating students' engagement in this behavior through the framework offered by the cognitive appraisal theory of stress may shed light on the relationship between university students' perceived stress and their tendency to turn to substance use as a coping resource.

\section{STUDENT FACTORS}

Additional factors that may influence the relationship between perceived stress and alcohol or drug use to cope could include student factors such as gender, program of study, and year of study. Gender differences are well documented for the stress experience among university students, with females reporting significantly higher levels of stress compared to males (Brougham et al., 2009; Dixon \& Kurpius, 2008; Economos, Hildebrandt, \& Hyatt, 2008). Another student factor that should be taken into account, particularly with respect to university students' stress is their program of study. May and Csazza (2012) found that students' program of study was a significant predictor of perceived stress by comparing stress levels between students enrolled in different programs based on the number of math, chemistry, and biology 
(MCB) courses that were required to complete the specific program. Students enrolled in programs that required 6 or more MCB courses of any combination (e.g., nursing, dental, premed, pharmacy, or engineering) reported significantly higher levels of stress compared to students enrolled in programs that required less than $6 \mathrm{MCB}$ courses (e.g., history, psychology, languages, or business). The difference in students' level of perceived stress based on program of study remained even after controlling for factors such as age, gender, and year in school. As such, it is important to consider program of study as a factor when examining stress among university students.

In terms of coping behaviors, Rutledge and Sher (2001) found that male university students were more likely to endorse drinking to cope compared to female university students; however, the literature on coping through illicit drug use lacks assessment of gender differences (McCabe et al., 2005). In terms of use, males were more likely than females to have used cannabis in the Canadian campus survey conducted by Adlaf et al. (2005); however, there were no significant gender differences in the use of other illicit drugs. Therefore, gender differences should be taken into account when assessing the relationship between perceived stress and using alcohol or drugs to cope.

Another student factor to note when investigating students' experiences of stress and coping behaviors is the year of study. Unfortunately, the literature is scant on reports of perceived stress over the different years in university. Bewick, Koutsopoulou, Miles, Slaa, and Barkham (2010) conducted a longitudinal investigation of 24,234 university students' psychological well-being in a UK university from preregistration to the final semester of their third year (the final year of university in the UK system). The study reported a significant decrease in psychological well-being among university students over their time in university. 
Although the psychological well-being variable was not assessing perceived stress directly, this finding is indicative of potential differences in students' psychological perceptions across the different years of study. Adlaf and colleagues (2005) reported that consumption of alcohol in a Canadian campus sample was higher among students in Year 4 compared to students in Year 1, although the difference was not observed for use of illicit drugs. Therefore, documenting the differences in perceived stress and coping behaviors in the different years of study could further demonstrate the needs of students in all years of university.

Although there is a solid body of literature examining university students' experiences of stress and patterns of coping, certain complexities remain to be explored. Stress as well as the problematic use of alcohol and illicit drugs on university campuses are issues of concern for university communities (Adlaf et al., 2005). The adverse effects of stress and substance use may be exacerbated when students engage in substance use to cope with stress (Kuntsche et al., 2005). As such, it is imperative to understand the patterns of both stress and coping through substance use (alcohol or drugs) among university students; however, it is also important to investigate the relationship between these variables. This raises the question: Might increases in stress be contributing to students' decision to turn to substances to cope? In light of Lazarus and Folkman's (1984) cognitive appraisal theory of stress, the elevated levels of stress students experience in university may contribute to their decision to engage in substance use as a coping mechanism. Thus, it might be of interest to examine whether heightened stress predicts the engagement in substance use as a coping strategy among university students. In light of the documented differences in gender, program of study, and year of study on the affects of stress and engagement in substance use within the university student population, it is also important to include these factors in the analysis. 
Our first objective for this study was to examine the patterns of stress reported by males and females across different years in university and programs of study, with the associated hypotheses that students' reports of perceived stress would differ by program of study (H1) and females will report significantly higher levels of stress compared to males (H2). The second objective was to examine the patterns of coping through frequent substance use by males and females across different years in university, whereby it was hypothesized that females would be significantly less likely compared to males to report coping through frequent alcohol (H3) and drug use (H4). The third objective was to examine whether reported stress is a predictor of frequent substance use as a coping strategy, with the associated hypotheses that stress would significantly positively predict frequent alcohol (H5) and frequent drug use (H6) as coping strategies. In the absence of related research, an exploratory approach was undertaken to investigate the possible differences in the relation between perceived stress and coping through frequent alcohol or drug use by year of study.

\section{METHOD}

This study was conducted in a large, urban university where the majority of the students live within close proximity of the central, downtown campus. This survey was conducted as part of an initial large-scale brief survey to establish a database of participants who had consented to being contacted for future studies. Data collection took place over the 2014-15 and 2015-16 academic years following a cross-sectional design, whereby students who self-reported as having participated in the study in both phases of the data collection were separated out as a distinct sample not included in the study presented here. Participating students were entered into a raffle for a chance to win one of three $\$ 100$ gift cards for each semester of data collection: Fall 2014, 
Winter 2015, and Fall 2015. Students consented to participate in the study through signed consent forms. All procedures were approved by the university research ethics board.

Courses for data collection were identified and selected with the goal of reaching as many students as possible while minimizing disruption for the instructors and students. In order to obtain a sample representative of all the faculties within the university, the largest courses in each faculty were selected based on their course capacity, in line with our goal to reach as many students as possible at one time. A total of 53 courses representative of the faculties within the university were selected for data collection in the 2014-15 academic year, and 36 courses were selected the following year. Instructors for the selected courses were contacted ahead of time to obtain permission to carry out data collection, which took place in a total of 24 courses in 201415 and in 29 courses in 2015-16. Surveys were then administered in class once a research assistant read a script to the class describing the purpose of the study. Students were informed that they were not obligated to complete the survey and that their participation would have no effect on their grade in the course. Students were notified that all identifying information would remain confidential and accessible only by core members of the research team. Participants were asked to complete the survey in class. The envelopes containing all surveys were collected by the researchers as students exited the lecture hall. Total response rate for survey completion was $61 \%$. Although a higher response rate may be expected for a captive audience such as students in a classroom, the large size of many of the classes in this university (e.g., 500-700 students) made opting out more feasible due to the anonymity within the large class; the crowd factor, among others, may also have contributed. Even though the final response rate was somewhat lower than expected, it was deemed acceptable given the large number of students that were approached. 
Participants consisted of 6,338 students $\left(65.2 \%\right.$ female; $M_{\text {age }}$ in years $=19.29, S D$ in years $=1.97)$ from a large Canadian university. Note that in Quebec students from out of the province begin at Year 0 due to preuniversity formation programs, which in-province students are required to complete. The preuniversity institutions are referred to as Collèges d'enseignement general et professionel (Colleges of General and Professional Education) or CEGEP (Edwards, 1990). Students who have obtained a CEGEP diploma prior to entering university are deemed to have completed prerequisite courses for the corresponding program at the university level and thus enter at Year 1; whereas students who do not have a CEGEP diploma upon entering university must complete a year of prerequisite courses (Year 0). Therefore, the traditional 4 years of university correspond to Years 0-3 in Quebec. By examining year of study as a factor within the Quebec context, our research also offers a unique opportunity to advance understanding of differences in stress and coping that may arise as a result of the CEGEP system. In this study 1,726 students were in Year 0; 2,582 in Year 1; 999 in Year 2; and 610 in Year 3.

\section{Measures}

Perceived Stress Scale. The 4-item Perceived Stress Scale (PSS-4; Cohen et al., 1983) was used to measure stress. The PSS is a measure designed to assess global appraisal of stress. Although longer versions of the PSS exist, the 4-item version was preferred as it is quicker to administer. Items address specific perceptions of stress in the last month (e.g., In the last month, how often have you felt that you were unable to control the important things in your life?). Participants were asked to respond to each item using a 5-point Likert-type scale ranging from 1 (never) to 5 (very often). The internal consistency for our sample was adequate $(\alpha=.77)$. 
Reliability of this scale within an earlier study was calculated to be at a similar level $(\alpha=.72)$, thus our measure of reliability was deemed acceptable.

Coping Questionnaire. Coping behaviors were assessed in the survey using a single question for each coping behavior (i.e., alcohol and drug use). Students were asked to indicate whether they have used the listed behavior to cope with stress by circling one of the following options; yes, no, not sure (e.g., Please read each of the following behaviors and indicate whether you have used the behavior to cope with stress). The behaviors listed included frequent alcohol use and frequent drug use (e.g., recreational drugs, hard drugs, illegal prescription drugs). For both behaviors, frequent was defined as most days of the week. Although frequent drinking has been defined as 3 or more days of the week in previous studies (Bonomo, Bowes, Coffey, Carlin, \& Patton, 2004), the decision to define it as most days was made to clarify the cutoff and to use the same standard for both alcohol and drug use.

\section{Data Cleaning and Analysis}

In the original sample, 284 participants indicated either an invalid year of study or being at the graduate level and were excluded from further analyses. Individuals indicating their gender identity as trans or not listed ( $n=33,0.52 \%$ of total sample) were excluded from subsequent analyses due to sample size limitations. Individuals who did not answer all 4 items of the PSS-4 were also excluded from the analysis $(n=88)$. Outliers were assessed by calculating z scores for the PSS-4. Although no multivariate outliers were found, a total of 16 univariate outliers $( \pm 3$ $S D s$ ) were identified and excluded from subsequent analyses. Thus, $6.64 \%$ of the sample was excluded, resulting in a final sample consisting of 5,917 individuals $\left(M_{\text {age }}=19.19, S D=1.97\right.$, $65.19 \%$ female). 
After data cleaning, factorial ANOVAs were conducted to examine the patterns of stress reported by males and females across different years in university and programs of study in line with the first objective of the study. For the second objective, separate chi-square analyses were conducted to examine the patterns of coping through frequent substance use by males and females across different years in university. For this analysis, participants indicating an answer of not sure to the coping question were not included. The third objective was investigated using separate logistic regression analyses (disaggregated by gender) to determine whether stress is a significant predictor of students' reports of coping through substance use. To examine gender differences in the relation between stress and coping through substance use, the technique outlined by Cumming (2009) was used to compare odds ratios for stress predicting engagement in substance use coping for males and females. This is a technique comparing the overlap in confidence intervals (CIs) of separate regression models whereby the percentage of overlap between two CIs can indicate whether there are significant differences between the odds ratios in question (e.g., an overlap of up to $50 \%$ in CIs can denote a significant difference at the $p=.05$ level).

\section{RESULTS}

\section{Objective 1: Pattern of Stress, Gender, Program, and Year of Study}

Our first objective was to examine patterns of perceived stress for males and females across the different years and programs of study. An initial factorial ANOVA was conducted to determine whether there were differences in perceived stress based on gender and program of study. 
In order to run this analysis, 1,062 participants had to be excluded due to their program of study being either missing or uninterpretable (e.g., responses such as "undeclared," "don't know," or "unsure," and illegible responses could not be categorized as any of the programs at the university). The remaining 4,747 participants $\left(M_{\text {age }}=19.24, S D=1.713,64.3 \%\right.$ Female $)$ were categorized according to the following 10 programs: Agriculture and Environmental Science, Arts and Humanities, Business and Commerce, Computer Science, Education, Engineering, Fine Arts, Professional Medicine, Pure and Applied Science, and Social Science. These categories are in accordance with the organization of faculties and departments at the university where this study took place.

The results from the two-way ANOVA, where perceived stress was the dependent variable and gender and program of study were the independent variables, revealed a nonsignificant interaction $(p=.09)$, and was rerun as a main effects model. As hypothesized (H1), results from this analysis revealed significant differences in reports of perceived stress based on program of study, $F(9,4,736)=4.914, p<.001, \eta_{p}^{2}=.01$, and gender, $F(1,4,746)=$ 92.703, $p<.001, \eta_{p}^{2}=.02$, albeit with small effect sizes. Scheffe post hoc comparisons were conducted to assess the differences observed between the programs, as this analysis allows for uneven sample sizes across groups (Ruxton \& Beauchamp, 2008). Interestingly, students in Education reported significantly higher levels of perceived stress compared to students in Arts and Humanities, .477, 95\% CI [.03, .92], Business and Commerce, 1.020, 95\% CI [.45, 1.59], Engineering, .913, 95\% CI [.47, 1.36], as well as Pure and Applied Sciences, .500, 95\% CI [0.1, $.91]$. 


\section{Stress Scores on PSS-4 for Male and Female Students by Year of Study}

The above analysis was conducted to examine the differences in stress across gender and program of study prior to examining the differences in stress across gender and year of study. Although the results revealed differences in stress based on program of study, this variable could not be further split by gender and year of study due to extremely small cell sizes $(\mathrm{n}<5)$. To address this issue and further understand the role of gender, program of study, and year of study on stress, a follow-up regression was conducted to examine whether these variables would be predictive of stress. In the absence of a theoretical rationale for selecting a reference group for the program of study variable in the regression, the largest group (Pure and Applied Sciences, $n$ $=1,504)$ was used as the reference. Gender and program of study were entered in the first step resulting in a significant equation, $F(2,4,744)=71.483, p<.001$, with $R^{2}=.03$; however, only gender was significant, $\beta=.17, p<.001$. Adding in year of study in the next step also yielded a significant regression equation, $F(1,4,743)=56.349, p<.001$, with $R^{2}=.04$. Both gender, $\beta=$ $.16, p<.001$ ), and year of study, $\beta=.11, \mathrm{p}<.001$, were significant predictors of stress; however, program of study was not significant, $\beta=-.007, p=.603$. Given this result, program of study was not included in any further analyses, and the original sample of 5,917 was used.

We hypothesized that female students would report significantly higher levels of stress compared to male students (H2). Although no specific hypotheses were made, we also aimed to explore (a) the differences in reports of stress cross-sectionally across the years of study in university, and (b) whether the expected gender differences were affected by year of study. A $2 \times$ 4 (Gender $\times$ Year of Study) ANOVA was carried out to test for differences in reports of stress with gender and year of study as the independent variables. As the interaction was not 
significant, $p=.12$, the ANOVA was conducted again as a main effects model. Results revealed significant differences in reports of stress by gender, with females reporting higher levels of stress, $F(1,5,916)=159.075, p<.001, \eta_{p}^{2}=.03$, and by year of study, $F(3,5,916)=21.582, p<$ $.001, \eta_{p}^{2}=.01$, where higher stress was reported in the later years of study compared to the earlier years. Once again, the effect sizes were small.

The means for each year of study are displayed graphically in Figure 1. As shown, participants in Year 2 of their studies reported the highest levels of stress. Scheffe post hoc comparisons revealed significant differences in reported levels of stress between Year 0 and Year 2, 0.89, 95\% CI [0.58, 1.20], and Year 1 and Year 2, 0.71, 95\% CI [0.41, 1.00]. The comparison between Year 2 and Year 3 was not significant, 0.28, 95\% CI [-0.13, 0.68].

\section{Objective 2: Pattern of Coping, Gender, Year of Study}

The second objective of the study was to examine the patterns of substance use coping for males and females by year of study. In order to assess the hypothesis that female students would be significantly less likely to endorse coping through frequent alcohol (H3) and frequent drug use (H4), two separate chi-square analyses were conducted. It should be noted that students who indicated the answer of not sure for using alcohol $(n=220,3.7 \%$ of sample) or drugs ( $n=$ $130,2.2 \%$ of sample) to cope with stress were excluded from the respective analyses. As hypothesised, females were significantly less likely to report coping through frequent alcohol use, $\chi 2(1)=11.36, p<.001$, and frequent drug use, $\chi 2(1)=36.95, p<.001$, compared to males. The association between gender and frequent alcohol use to cope with stress was small, $\Phi=$ $0.05, p<.001$, and similar to the association between gender and frequent drug use for the explicit purpose of coping with stress, $\Phi=0.08, p<.001$. 
Finally, although no explicit hypotheses were made, the differences in reports of coping through frequent alcohol and drug use were also examined by year of study separately for males and females. Overall, year of study had a significant effect on students' reports of coping through frequent alcohol use for both males, $\chi 2(3)=15.09, p<.002$, and females, $\chi 2(3)=24.10, p<$ .001. Interestingly, year of study only significantly affected reports of coping through frequent drug use for males, $\chi 2(3)=23.45, p<.001$, but no significant effect of year of study was observed for females, $\chi 2(3)=6.62, p=.085$. See Table 1 .

\section{Objective 3: Stress as a Predictor of Coping Through Substance Use}

The third objective of the study was to examine whether levels of perceived stress predicted students' engagement in coping through substance use. Two separate binomial logistic regressions were carried out to test the hypothesis that stress would be a significant predictor of students' coping through frequent alcohol use (H5) and frequent drug use (H6); the regression models for both were disaggregated by gender. The independent variables in the equation were stress score and year of study (divided into 4 separate variables representing each year of study) and were entered in one model. Year 0 was determined as the reference group for this analysis as it is the earliest possible year in university. Subsequent years were compared to Year 0 to evaluate differences in reports of coping through frequent alcohol use as the dependent variable. The logistic regression model for the effects of stress on coping through frequent alcohol use was statistically significant for both males, $\chi 2(4)=70.870, p<.001$, and females, $\chi 2(4)=91.782, p<$ .001 . The model explained $4.9 \%$ (Nagelkerke R2) of the variance in frequent alcohol use to cope with stress for males and $6.6 \%$ of the variance for females, indicating small effect sizes. Percentage accuracy in classification was $87.7 \%$ for males and $84.4 \%$ for females. The CIs for males and females were also compared to test for gender differences in the regression model for 
stress predicting coping through frequent alcohol use. This analysis was conducted employing methodology outlined by Cumming (2009), and no statistically significant differences were found based on the substantial overlap of CIs.

\section{Percentage of Students Engaging in Coping Behaviors by Gender and Year of Study}

Among male students, those in Year 1 were 1.4 times $(p<.035)$ more likely to report frequent consumption of alcohol to cope with stress and those in Year 2 were 1.7 times $(p<$ .007) more likely, compared to Year 0. Interestingly, female students were 2.1 times $(p<.001)$ more likely to report coping through frequent alcohol use in Year 3 compared to Year 0. See Table 2.

The logistic regression model for the effects of stress on coping through frequent drug use was also statistically significant for both males, $\chi 2(4)=55.951, p<.001$, and females, $\chi 2(4)$ $=51.709, p<.001$. The model explained $5.7 \%\left(\right.$ Nagelkerke $\left.R^{2}\right)$ of the variance in reports of coping through frequent drug use for males and $3.6 \%$ of the variance for females, which is considered a small effect size. Percentage accuracy of classification was $88.1 \%$ for males and $93.0 \%$ for females. Overall, males were 2.1 times $(p<.001)$ more likely to report engaging in frequent drug use to cope with stress in Year 2 compared to Year 0. The model used to assess the effects of stress scores and year of study, as independent variables, on reports of coping through frequent drug use, as the dependent variable, for males and females was the same as the model used for examining the effect of stress and year of study on coping through frequent alcohol use (see Table 2). No statistically significant differences were found between males and females when comparing CIs employing Cumming's (2009) methodology.

\section{DISCUSSION}


We sought to examine the patterns of stress across gender and year in university as well as the use of alcohol or drugs to cope with stress. We also assessed stress as a potential predictor of using either alcohol or drugs specifically for the purposes of coping with stress. Findings from this study largely confirm the stated hypotheses, which included higher levels of stress reported by females compared to males, lower levels of coping through alcohol or drugs reported by females, higher stress levels reported in later years compared to the earlier transition years, and stress predicting students' engagement in coping through alcohol or drug use. Interestingly, this is the first study to demonstrate this pattern of stress co-occurring with students' reports of engaging in frequent alcohol and drug use as ways of coping with stress. These findings challenge the notion that the transition to university may be the most stressful time for students.

\section{Logistic Regression Predicting Engagement in Substance Use to Cope With Stress}

\section{Stress Patterns}

Results indicated that female students reported higher levels of stress overall compared to male students, and this gender difference remained regardless of year of study. This is consistent with previous literature examining gender differences in university students' reports of stress (Brougham et al., 2009; Durand-Bush et al., 2015; Economos et al., 2009); however, the nature of these differences is not well explained (Brougham et al., 2009). Economos et al. (2008) suggested that one factor contributing to this gender difference may reside in how individuals react to stress (i.e., their coping responses). The greater use of emotion-focused coping by women is believed to be the result of socialization (Brougham et al., 2009) and thought to possibly contribute to the way women perceive their experienced stress. Moreover, a study by Dyson and Renk (2006) revealed no gender differences in stress appraisals and coping strategies 
employed by university students. Therefore, further inquiry is warranted to better understand gender differences in reports of stress in university students.

The observed pattern of reported stress across year of study was an interesting finding: specifically, students reported the highest level of stress in their third year in university. This finding not only challenges the notion that stress is higher in the earlier transition years versus later years (Dyson \& Renk, 2006), but also suggests that stress levels may plateau in the third year. In light of the cognitive appraisal theory of stress (Lazarus \& Folkman, 1984), the increasing demands of life and academia may begin to seem daunting when students approach the end of their university studies as opposed to the earlier years when they might be more preoccupied with the excitement of exploring with only a mild discomfort due to adjusting to university. The challenges of later years (selecting a major, more difficult coursework, applications to internships and graduate school, etc.) may add to students' stress levels as they feel an increasing demand on their coping resources. Further research is necessary to unravel the possible mechanisms underlying the increase in student reports of stress over the years of study; however it is possible that planning for the approaching transition out of university and recognizing the remaining obstacles are significant stressors.

College student development is an important field of study that has received attention for many years. Developmental theories pertaining to university students have been proposed by scholars such as Chickering (1969) and Arnett (2000). Chickering's original proposal and the revised version (Chickering \& Ressier, 1993) of the theory propose seven vectors of personal development through which students progress during their time at university. Although the sequence of these vectors is not fixed or rigid, one of the more advanced vectors concerns the establishment of purpose. The increase in reports of stress in the later years may coincide with 
students' daunting tasks of understanding and conceptualizing their own purpose beyond the university degree. Similarly, Arnett's more recent developmental theory, the theory of emerging adulthood, includes an additional life-course stage preceding adulthood referred to as emerging adulthood, which emphasizes the distinct transition to adulthood that is faced by young adults today as opposed to those of earlier generations. For university students who are faced with the challenge to navigate the demands of this delayed transition to adulthood, the experience of career anxiety and the uncertainty of the transition to adulthood may appear to be a more overpowering sources of stress compared to the transition into university. Although it is not our intention to discuss the individual merits and shortcomings of these developmental theories, the common ground between the seven vector framework and the notion of emerging adulthood appears to be that the transition through university into adulthood can be challenging and uncertain. As such, approaching the end of university with independent adulthood in sight may contribute to the observed increase in levels of reported stress for students in higher years. Our findings support the notion that examining the experiences of university students as they progress through their studies should complement the widespread efforts to support students transitioning into university (Brougham et al., 2009).

\section{Coping Patterns}

Students' reports of coping through frequent substance use in different years of study followed a pattern similar to their reports of stress throughout the years. Among males, proportionately more students in their third year reported engaging in frequent alcohol use and frequent drug use as ways of coping with stress. Among females, significantly more students in their fourth year of university reported coping through frequent alcohol use. Male students' reports of coping through drug use followed a pattern similar to their reports of stress throughout 
the years of study, in which a greater proportion of students endorsed this behavior in later years of study. Interestingly, there were no differences based on year of study for females' reports of engaging in frequent drug use to cope with stress. Overall, the proportion of females reporting coping through frequent drug use was lower than that of males.

In a study that was designed to obtain students' perspectives of their drinking behavior, Collins and colleagues (2014) found that university students reported coping with stress as one of the main motivations behind drinking. Our findings are consistent with this view, given the parallel pattern observed for stress and coping through substance use within our sample. Further inquiry is needed to conclude the nature of this link; however, the increased proportion of females compared to males reporting coping through frequent alcohol use in their final year challenges the findings of Rutledge and Sher (2001) that being male and of drinking age were main predictors of university students' engagement in stress-related drinking. Rutledge and Sher interpreted these gender differences in light of cultural norms allowing for males' engagement in drinking to cope with stress, while being more critical of this behavior for females. Although this interpretation may have been grounded at the time the Rutledge and Sher study was conducted, attitudes towards female drinking have since changed (Kaya, Iwamoto, Grivel, Clinton, \& Brady, 2016). In light of our contradictory findings, alternative explanations for the observed differences in students' reports of engaging in this behavior are needed. One possibility may be a more pronounced manifestation of unhealthy coping behaviors, such as frequent alcohol use, among female students reporting higher stress.

Students' reports of engaging in frequent drug use to cope with stress also demonstrated gender differences in our study with a significantly greater proportion of males engaging in this behavior compared to females. This finding is consistent with previous literature reporting higher 
rates of drug use and abuse among male university students (McCabe et al., 2007). Interestingly, the proportion of female students reporting coping through drug use remained relatively constant in the different years of study despite their reports of higher stress in later years. In contrast, the proportion of male students engaging in this behavior increased in the later years, in line with their reports of higher stress. In agreement with previous literature that cites gender differences in coping preferences and styles (Brougham et al., 2009), this finding illustrates that there may be factors which influence coping preferences based on gender. Although the nature of these differences cannot be determined based on the broad nature of our study, the findings contribute to the literature on university students' coping preferences as they relate to their reports of stress. Although the effect of perceived stress in predicting students' engagement in substance use to cope is rather small, the model is significant nonetheless, suggesting that higher levels of perceived stress contribute to an increased tendency to engage in unhealthy coping behaviors within this sample. Stress was found to play a similar role in predicting coping through substance use for both male and female students, further challenging the preconceptions around genderbased coping preferences and substance use behaviors (Dyson \& Renk, 2006; Kaya et al., 2016). It is beyond the scope of this study to provide a comprehensive view of all of the factors that lead to students' engagement in substance use as a coping strategy. Further investigation is needed to examine other individual and institutional factors that play a role in the development and maintenance of unhealthy coping behaviors.

\section{LIMITATIONS AND RECOMMENDATIONS}

Although our analyses demonstrate meaningful relations between the observed variables, the results must be interpreted with caution due to small effect sizes. Similarly, the variability in coping through substance use explained by stress was small, which should be taken into 
consideration when interpreting our findings. The cross-sectional nature of this investigation is also limited in explaining the developmental trajectories of the variables in question. Although differences in stress and coping behaviors were observed for students in different years of study, how these changes came about and the progression of changes from Year 0 all the way to Year 3 cannot be explained. Furthermore, the potential influence of the CEGEP system on the university experiences of in-province students in Quebec should be explored by future studies. Due to the nature of the questions, selection bias may have also played a role in the profile of participants who chose to complete the questionnaires; that is, students who were already struggling with stress and coping may have avoided participation, or conversely, may have been more likely to participate. An additional limitation is the restricted nature of the questionnaire due to time constraints and the intended nature of this survey as an initial, brief measure to establish a participant database. It is recommended that future researchers consider accounting for variables such as living situation (e.g., residence or commuting) and course load as potential factors contributing to stress, as well as factors such as individual or family history of substance abuse. Future studies employing longitudinal approaches are needed to understand the evolution of students' experiences with stress and their engagement in coping through substance use as they progress through university. Despite these limitations, this study is valuable in providing information on university students' experiences with stress and coping through substance use within a large postsecondary institution with a diverse student population.

\section{CONCLUSION}

These findings point to the presence of a relationship between levels of stress and students' reports of coping through frequent alcohol use and drug use in our university student sample. Even though heightened stress and substance use on campuses are not new problems, 
students' attributions of their substance use behavior to stress is noteworthy. Although there is a preconceived notion that university students engage in the misuse of alcohol and drugs for social reasons (see Kuntsche et al., 2005) and are somewhat expected to mature out of the behavior pattern as they get older (see Arria et al., 2016), it is becoming increasingly important to address students' engagement in substance use for the explicit purpose of coping, particularly in light of both the increasing reports of stress by university students (Durand-Bush et al., 2015) and the numerous studies that have established a positive link between coping motives behind substance use and ensuing substance use problems (Collins et al., 2014; Kuntsche et al., 2005; Merrill, Wardell, \& Read, 2014; Rutledge \& Sher, 2001; Tomaka et al., 2013). In addition to the negative consequences of problematic substance use on individuals' health and well-being (Collins et al., 2014), this behavior can also have traumatic effects on other people through secondary encounters, effects ranging from sleep or study disturbances all the way up to the trauma of sexual assault (Adlaf et al., 2005), the latter a particular concern on university campuses.

Alcohol and other substances will continue to exist for university students and many will continue to engage in substance misuse. While research and intervention efforts have focused on the well-being of students transitioning into university and in the early years (Dyson \& Renk, 2006, Conley, Kirsch, Dickson, \& Bryant, 2014), literature has shown that students transitioning out of university appear to report more difficulties on measures of mental health and well-being (Beiter et al., 2017; Bewick et al., 2010; Mahmoud, Staten, Hall, \& Lennie, 2012). Although this is a single-institution study, our findings demonstrate that the transition out of university is a challenging period worthy of inquiry. Although one would expect students to resort to healthier coping strategies as they progress through their university education, we did not find this to be the case in our sample. In line with numerous other studies reporting on the stress and coping 
challenges faced by university students across Canada (e.g., Digdon \& Landry, 2013; DurandBush et al., 2015; Klassen \& Durksen, 2014; Regehr, Glancy, \& Pitts, 2012), our findings demonstrate an urgent need for approaches that offer to students healthy coping and stress tolerance strategies to alleviate the negative progression of student stress and unhealthy coping. Understanding the factors that lead to problematic substance use on university campuses can provide an improved framework to address these pressing issues and implement practices that protect students and reduce harm. 


\section{References}

Adlaf, E. M., Demers, A., \& Gliksman, L. (2005). Canadian campus survey 2004. Toronto, ON: Centre for Addiction and Mental Health. Retrieved from http://www.ontla.on.ca/library/repository/mon/25005/309709.pdf

American College Health Association. (2016). ACHA-National College Health Assessment II: Canadian reference group data report Spring 2016. Hanover, MD: ACHA. Retrieved from http://www.acha.org/documents/ncha/NCHA-

II\%20spring\%202016\%20canadian\%20reference\%20group\%20data\%20report.pdf

American College Health Association. (2018) ACHA-National College Health Assessment II:

Undergraduate student reference group executive summary Spring 2018. Silver Spring, MD: Author. Retrieved from http://www.acha.org/documents/ncha/NCHAII_Spring_2018_Undergraduate_Reference_Group_Executive_Summary.pdf

Arnett, J. J. (2000). Emerging adulthood: A theory of development from the late teens through the twenties. American Psychologist, 55, 469-480.

Arria, A. M., Caldeira, K. M., Allen, H. K., Vincent, K. B., Bugbee, B. A., \& O’Grady, K. E. (2016). Drinking like an adult? Trajectories of alcohol use patterns before and after college graduation. Alcoholism: Clinical and Experimental Research, 40, 583-590. doi:10.1111/acer.12973

Arria, A. M., Caldeira, K. M., Bugbee, B. A., Vincent, K. B., \& O’Grady, K. E. (2015). The 
academic consequences of marijuana use during college. Psychology of Addictive Behaviors, 29, 564-575.

Beiter, R., Nash, R., McCrady, M., Rhoades, D., Linscomb, M., Clarahan, M., \& Sammut, S. (2015). The prevalence and correlates of depression, anxiety, and stress in a sample of college students. Journal of Affective Disorders, 173, 90-96.

Bewick, B., Koutsopoulou, G., Miles, J., Slaa, E., \& Barkham, M. (2010). Changes in undergraduate students' psychological well-being as they progress through university. Studies in Higher Education, 35, 633-645. doi:10.1080/03075070903216643

Bonomo, Y. A., Bowes, G., Coffey, C., Carlin, J. B., \& Patton, G. C. (2004). Teenage drinking and the onset of alcohol dependence: a cohort study over seven years. Addiction, 99, $1520-1528$.

Brougham, R. R., Zail, C. M., Mendoza, C. M., \& Miller, J. R. (2009). Stress, sex differences, and coping strategies among college students. Current Psychology, 28, 85-97.

Chen, Y., \& Feeley, T. H. (2015). Predicting binge drinking in college students: Rational beliefs, stress, or loneliness? Journal of Drug Education, 45, 133-155.

Chickering, A. W. (1969). Education and identity. San Francisco, CA: Jossey-Bass.

Chickering, A. W., \& Reisser, L. (1993). Education and identity (2nd ed.). San Francisco, CA: Jossey-Bass.

Childs, S. E., Finnie, R., \& Martinello, F. (2016). Postsecondary student persistence and 
pathways: Evidence from the YITS-A in Canada. Research in Higher Education, 58, 270-294. doi:10.1007/s11162-016-9424-0

Cohen, S., Kamarck, T., \& Mermelstein, R. (1983). A global measure of perceived stress. Journal of Health and Social Behavior, 24, 385-396.

Coleman, J., \& Trunzo, J. (2015). Personality, social stress, and drug use among college students. Psi Chi Journal of Psychological Research, 20, 52-56.

Collins, S. E., Kirouac, M., Taylor, E., Spelman, P. J., Grazioli, V., Hoffman, G., . . Hicks, J. (2014). Advantages and disadvantages of college drinking in students' own words: Content analysis of the decisional balance worksheet. Psychology of Addictive Behaviors, 28, 727-733. doi:10.1037/a0036354

Conley, C. S., Kirsch, A. C., Dickson, D. A., \& Bryant, F. B. (2014). Negotiating the transition to college: Developmental trajectories and gender differences in psychological functioning, cognitive-affective strategies, and social well-being. Emerging Adulthood, 2, $195-210$.

Cooper, M. L. (1994). Motivations for alcohol use among adolescents: Development and validation of a four-factor model. Psychological Assessment, 6, 117.

Cox, W. M., \& Klinger, E. (1988). A motivational model of alcohol use. Journal of Abnormal Psychology, 97, 168-180.

Cumming, G. (2009). Inference by eye: Reading the overlap of independent confidence intervals. 
Statistics in Medicine, 28, 205-220.

Dermody, S. S., Cheong, J., \& Manuck, S. (2013). An evaluation of the stress-negative affect model in explaining alcohol use: The role of components of negative affect and coping style. Substance Use \& Misuse, 48, 297-308.

Digdon, N., \& Landry, K. (2013). University students' motives for drinking alcohol are related to evening preference, poor sleep, and ways of coping with stress. Biological Rhythm Research, 44, 1-11.

Dixon, S. K., \& Kurpius, S. E. (2008). Depression and college stress among university undergraduates: Do mattering and self-esteem make a difference? Journal of College Student Development, 49, 412-424.

Durand-Bush, N., McNeill, K., Harding, M., \& Dobransky, J. (2015). Investigating stress, psychological well-being, mental health functioning, and self-regulation capacity among university undergraduate students: Is this population optimally functioning? Canadian Journal of Counselling and Psychotherapy, 49, 253-274.

Dyson, R., \& Renk, K. (2006). Freshmen adaptation to university life: Depressive symptoms, stress, and coping. Journal of Clinical Psychology, 62, 1231-1244.

Economos, C. D., Hildebrandt, M., \& Hyatt, R. R. (2008). College freshman stress and weight change: Differences by gender. American Journal of Health Behavior, 32, 16-25.

Edwards, R. (1990). Historical background of the English-language CEGEPs of Quebec. McGill 
Journal of Education / Revue des sciences de l'éducation de McGill, 25, 147-174.

El Ansari, W., Adetunji, H., \& Oskrochi, R. (2014). Food and mental health: Relationship between food and perceived stress and depressive symptoms among university students in the United Kingdom. Central European Journal of Public Health, 22, 90-97. doi:10.21101/cejph.a3941

Galambos, N. L., Vargas Lascano, D. I., Howard, A. L., \& Maggs, J. L. (2013). Who sleeps best? Longitudinal patterns and covariates of change in sleep quantity, quality, and timing across four university years. Behavioral Sleep Medicine, 11, 8-22.

Goldstein, A. L., \& Flett, G. L. (2009). Personality, alcohol use, and drinking motives: A comparison of independent and combined internal drinking motives groups. Behavior Modification, 33, 182-198. doi:10.1177/0145445508322920

Holinka, C. (2015). Stress, emotional intelligence, and life satisfaction in college students. College Student Journal, 49, 300-311.

Holloway, K., Bennett, T., Parry, O., \& Gorden, C. (2014). Characteristics and consequences of prescription drug misuse among university students in the United Kingdom. Journal of Substance Use, 19, 156-163. doi:10.3109/14659891.2013.765513

Kaya, A., Iwamoto, D. K., Grivel, M., Clinton, L., \& Brady, J. (2016).The role of feminine and masculine norms in college women's alcohol use. Psychology of Men \& Masculinity, 17, 206-214.

Klassen, R. M., \& Durksen, T. L. (2014). Weekly self-efficacy and work stress during the 
teaching practicum: A mixed methods study. Learning and Instruction, 33, 158-169.

Kuntsche, E., Knibbe, R., Gmel, G., \& Engels, R. (2005). Why do young people drink? A review of drinking motives. Clinical Psychology Review, 25, 841-861.

Lazarus, R. S., \& Folkman, S. (1984). Stress, appraisal, and coping. New York, NY: Springer.

Lovell, G. P., Nash, K., Sharman, R., \& Lane, B. R. (2015). A cross-sectional investigation of depressive, anxiety, and stress symptoms and health-behavior participation in Australian university students. Nursing \& Health Sciences, 17, 134-142.

Mahmoud, J. S. R., Staten, R. T., Hall, L. A., \& Lennie, T. A. (2012). The relationship among young adult college students' depression, anxiety, stress, demographics, life satisfaction, and coping styles. Issues in Mental Health Nursing, 33, 149-156.

May, R. W., \& Csazza, S. P. (2012). Academic major as a perceived stress indicator: Extending stress management intervention. College Student Journal, 46, 264-273.

McCabe, S. E., Knight, J. R., Teter, C. J., \& Wechsler, H. (2005). Non-medical use of prescription stimulants among US college students: Prevalence and correlates from a national survey. Addiction, 100, 96-106.

McCabe, S. E., Morales, M., Cranford, J. A., Delva, J., McPherson, M. D., \& Boyd, C. J. (2007). Race/ethnicity and gender differences in drug use and abuse among college students. Journal of Ethnicity in Substance Abuse, 6(2), 75-95.

Merrill, J. E., \& Read, J. P. (2010). Motivational pathways to unique types of alcohol 
consequences. Psychology of Addictive Behaviors, 24, 705-711. doi:10.1037/a0020135

Merrill, J. E., Wardell, J. D., \& Read, J. P. (2014). Drinking motives in the prospective prediction of unique alcohol-related consequences in college students. Journal of Studies on Alcohol and Drugs, 75, 93-102.

Palmer, A., \& Rodger, S. (2009). Mindfulness, stress, and coping among university students. Canadian Journal of Counselling and Psychotherapy, 43, 198-212. Retrieved from http://cjc-rcc.ucalgary.ca.proxy3.library.mcgill.ca/cjc/index.php/rcc/article/view/648

Pluut, H., Curşeu, P. L., \& Ilies, R. (2015). Social and study related stressors and resources among university entrants: Effects on well-being and academic performance. Learning and Individual Differences, 37, 262-268.

Price, E. L., McLeod, P. J., Gleich, S. S., \& Hand, D. (2006). One-year prevalence rates of major depressive disorder in first-year university students. Canadian Journal of Counselling and Psychotherapy, 40, 68-81. Retrieved from http://cjcrcc.ucalgary.ca.proxy3.library.mcgill.ca/cjc/index.php/rcc/article/view/291/633

Regehr, C., Glancy, D., \& Pitts, A. (2013). Interventions to reduce stress in university students: A review and meta-analysis. Journal of Affective Disorders, 148, 1-11.

Rutledge, P. C., \& Sher, K. J. (2001). Heavy drinking from the freshman year into early young adulthood: The roles of stress, tension-reduction drinking motives, gender and personality. Journal of Studies on Alcohol, 62, 457-466.

Ruxton, G. D., \& Beauchamp, G. (2008). Time for some a priori thinking about post hoc testing. 
Behavioral Ecology, 19, 690-693. doi:10.1093/beheco/arn020

Sebena, R., El Ansari, W., Stock, C., Orosova, O., \& Mikolajczyk, R. T. (2012). Are perceived stress, depressive symptoms and religiosity associated with alcohol consumption? A survey of freshmen university students across five European countries. Substance Abuse Treatment, Prevention, and Policy, 7(1, article 21). doi:10.1186/1747-597X-7-21

Simons, J. S., Gaher, R. M., Correia, C. J., Hansen, C. L., \& Christopher, M. S. (2005). An affective-motivational model of marijuana and alcohol problems among college students. Psychology of Addictive Behaviors, 19, 326-334.

Sinha, R. (2008). Chronic stress, drug use, and vulnerability to addiction. Annals of the New York Academy of Sciences, 1141, 105-130.

Stoliker, B. E., \& Lafreniere, K. D. (2015). The influence of perceived stress, loneliness, and learning burnout on university students' educational experience. College Student Journal, $49,146-160$.

Tomaka, J., Morales-Monks, S., \& Shamaley, A. G. (2013). Stress and coping mediate relationships between contingent and global self-esteem and alcohol-related problems among college drinkers. Stress and Health, 29, 205-213.

Welle, P. D., \& Graf, H. M. (2011). Effective lifestyle habits and coping strategies for stress tolerance among college students. American Journal of Health Education, 42, 96-105.

Woolman, E. O., Becker, M. M., \& Klanecky, A. K. (2015). PTSD symptoms mediate academic 
stress and drinking to cope in college students. Journal of Drug Education, 45, 96-112.

\section{Tables and Figures}

Figure 1. Stress Scores on PSS-4 for Male and Female Students by Year of Study 


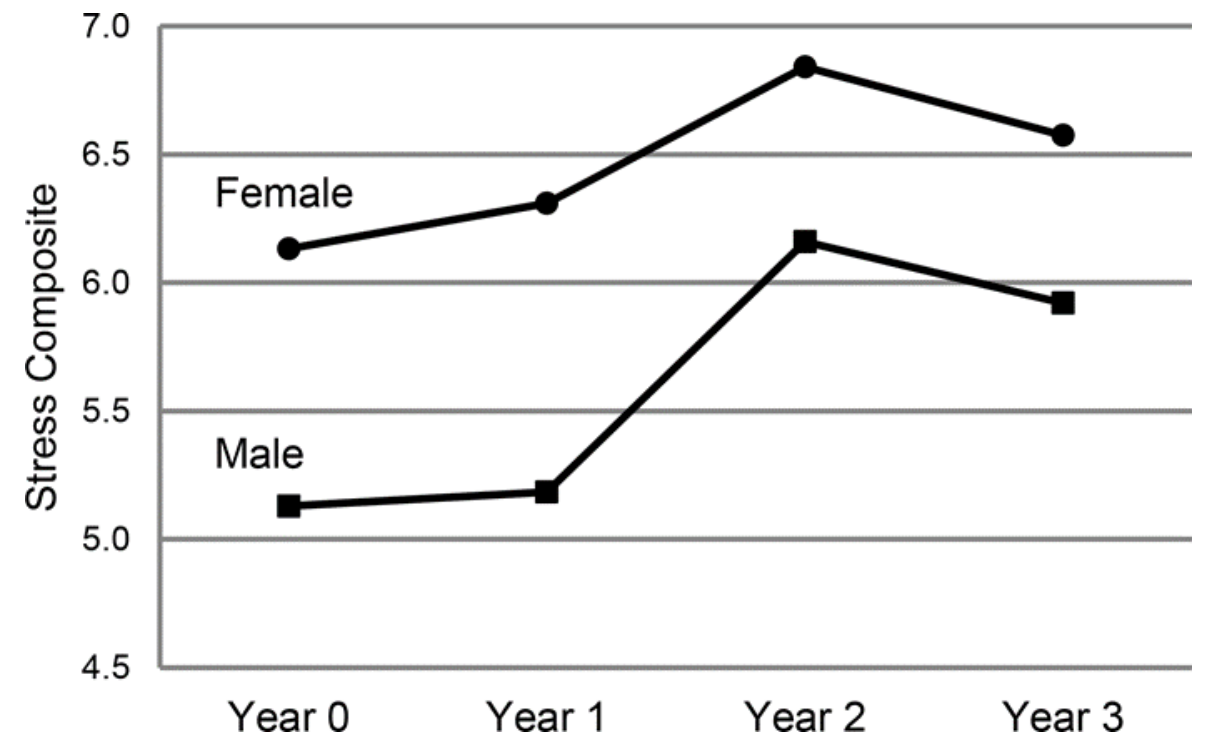

Table 1. Percentage of Students Engaging in Coping Behaviors by Gender and Year of Study

\begin{tabular}{llllll}
\hline Coping Behavior & Gender & Year $\mathbf{n}(\%)$ & Year $\mathbf{1} \boldsymbol{n}(\%)$ & Year $\mathbf{2} \boldsymbol{n}(\%)$ & Year $\mathbf{3}(\%)$ \\
\hline Frequent alcohol use & Male & $69_{\mathrm{a}}(11.66)$ & $122_{\mathrm{b}}(15.82)$ & $60_{\mathrm{c}}(21.20)$ & $34_{\mathrm{b}, \mathrm{c}}(18.68)$ \\
& Female & $92_{\mathrm{a}}(9.57)$ & $186_{\mathrm{b}}(12.14)$ & $79_{\mathrm{a}, \mathrm{b}}(12.52)$ & $72_{\mathrm{c}}(19.41)$ \\
\hline Frequent Drug use & Male & $53_{\mathrm{a}}(8.88)$ & $85_{\mathrm{a}, \mathrm{b}}(10.76)$ & $56_{\mathrm{c}}(19.58)$ & $27_{\mathrm{b}, \mathrm{c}}(14.44)$ \\
& Female & $51_{\mathrm{a}}(5.23)$ & $116_{\mathrm{b}}(7.46)$ & $52_{\mathrm{b}}(8.02)$ & $29_{\mathrm{a}, \mathrm{b}}(7.82)$ \\
\hline
\end{tabular}

Note. Within each row, the column proportions are compared using a $\mathrm{z}$ test. If a pair of values are significantly different at the .05 level, the values have different subscript letters assigned to them.

Table 2. Logistic Regression Predicting Engagement in Substance Use to Cope With Stress 


\begin{tabular}{|c|c|c|c|c|c|c|c|c|c|c|c|c|}
\hline & \multicolumn{6}{|c|}{ Frequent Alcohol Use $(N=5,323)$} & \multicolumn{6}{|c|}{ Frequent Drug Use $(N=5,410)$} \\
\hline & & $b$ & $S E$ & $d f$ & $p$ & OR & & $b$ & $S E$ & $d f$ & $p$ & OR \\
\hline $\begin{array}{l}\text { Stress } \\
\text { Score }\end{array}$ & $\begin{array}{l}\text { Male } \\
(n=1,828)\end{array}$ & .173 & .023 & 1 & .0 & $1.188^{*}$ & $\begin{array}{l}\text { Male } \\
(n=1,860)\end{array}$ & .149 & .025 & 1 & .0 & $1.160^{*}$ \\
\hline Year 0 & & & & 3 & .038 & & & & & 3 & .002 & \\
\hline Year 1 & & .345 & .164 & 1 & .035 & $1.413^{*}$ & & .210 & .186 & 1 & .258 & 1.234 \\
\hline Year 2 & & .536 & .198 & 1 & .007 & $1.708^{*}$ & & .763 & .211 & 1 & .0 & $2.145^{*}$ \\
\hline Year 3 & & .432 & .234 & 1 & .065 & 1.540 & & .443 & .256 & 1 & .084 & 1.558 \\
\hline $\begin{array}{l}\text { Stress } \\
\text { Score }\end{array}$ & $\begin{array}{l}\text { Female } \\
(n=3,495)\end{array}$ & .150 & .018 & 1 & .0 & $1.162^{*}$ & $\begin{array}{l}\text { Female } \\
(n=3,550)\end{array}$ & .153 & .023 & 1 & .0 & $1.165^{*}$ \\
\hline Year 0 & & & & 3 & .0 & & & & & 3 & .229 & \\
\hline Year 1 & & .232 & .136 & 1 & .087 & 1.262 & & .338 & .174 & 1 & .053 & 1.402 \\
\hline Year 2 & & 185 & .165 & 1 & .262 & 1.203 & & .345 & .206 & 1 & .094 & 1.403 \\
\hline Year 3 & & .743 & .174 & 1 & .0 & $2.102^{*}$ & & .333 & .243 & 1 & .171 & 1.404 \\
\hline
\end{tabular}

